\title{
Preparation and Characterisation of Polymer Electrolytes Containing Poly(vinylidene Fluoride-co- hexafluoropropylene) and Zinc Trifluromethanesulfonate
}

\author{
W. LILY MARGARET PRIYA ${ }^{\mathrm{a}}$ and S. AUSTIN SUTHANTHIRARAJ ${ }^{\mathrm{b}}$

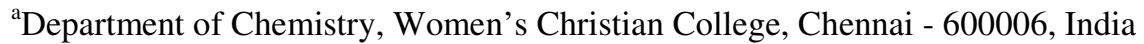 \\ ${ }^{\mathrm{b}}$ Department of Energy, University of Madras, Guindy Campus, Chennai - 600025, India \\ samuel_priya@yahoo.co.in
}

Received 7 March 2013 / Accepted 30 April 2013

\begin{abstract}
Polymer electrolyte (PE) materials consisting of poly(vinylidene fluoride-cohexafluoropropylene) (PVDF-HFP) and zinc trifluoromethanesulfonate (zinc triflate) were prepared and characterized in order to determine the composition with an optimum electrical conductivity. PE films of pure PVDF-HFP and various compositions containing 5, 10, 15, 20 and 25 weight percent of zinc triflate in a polymer matrix of PVDF-HFP were synthesized and analyzed using complex impedance analysis, x-ray diffraction (XRD) and differential scanning calorimetry (DSC) studies. The composition containing 25 weight percent of zinc triflate in PVDF-HFP polymer matrix was found to exhibit an optimum electrical conductivity $(\sigma)$ of $5.5 \times 10^{-5} \mathrm{Scm}^{-1}$ at room temperature (301 K).
\end{abstract}

Keywords: Polymer electrolyte, Complex impedance, XRD, PVDF-HFP, Zinc triflate, DSC

\section{Introduction}

Polymer electrolytes are being studied widely because of the ease in the preparation of polymer films for their practical applications in the case of rechargeable batteries, capacitors and sensors ${ }^{1-3}$. PE are free from several disadvantages such as risk of leakage of electrolyte, internal shorting and formation of non-combustible reaction products at the electrode surface that are observed in devices using liquid electrolytes. Hence the synthesis and standardization of PE is being widely undertaken ${ }^{4}$. Earlier, studies were conducted on PE consisting of alkali metal salts in a matrix formed by the well known polymer namely polyethylene oxide (PEO), but they were found to exhibit very poor ionic conductivity at room temperature. The low conductivity of PEO is attributed to high concentration of the crystalline phase ${ }^{5-7}$. Since then, research is being carried out with the view of discovering new PE systems involving various polymers and copolymers. One such polymer system that is being investigated is PVDF-HFP system.

The PVDF-HFP copolymer system exhibits good mechanical stability and readily forms films when it is dissolved in a suitable solvent and cast. The crystalline phase of PVDF-HFP 
consisting of VDF units provides the necessary mechanical support while the amorphous phase of the polymer consisting of HFP units facilitates easy ionic conductivity. PVDF-HFP exhibits a high dielectric constant $(\varepsilon)$ of 8.4 which enables it to accommodate a high concentration of charge carriers. The lone pair of electrons present on fluorine atoms in PVDF-HFP allows coordination of the polymer with the cation of a salt to form polymer-salt complexes $^{8-10}$. The strong electron withdrawing $(-\mathrm{C}-\mathrm{F})$ functional group in PVDF-HFP makes the polymer electrochemically stable and non-combustible ${ }^{11}$. Lithium trifluoromethanesulfonate which was used as the doping salt to furnish $\mathrm{Li}^{+}$ions for ionic conduction in polymer electrolytes is now being replaced by other potential ion sources such as zinc triflate which furnishes $\mathrm{Zn}^{2+}$ ions for conduction in the polymer matrix. The major advantages of using zinc include low equivalent weight, high specific energy, low cost, low toxicity, availability and ease of handling ${ }^{12}$.

In the present investigation, PE materials were obtained by incorporating varying weight percent of zinc triflate as the doping salt in PVDF-HFP polymer matrix using acetone as the common solvent in order to determine the best conducting composition. Characterization of these PE films was carried out using impedance analysis, differential scanning calorimetry and $\mathrm{x}$-ray diffraction studies.

\section{Experimental}

PVDF-HFP and zinc triflate were purchased from Aldrich (USA). The chosen polymer PVDF-HFP was dissolved in anhydrous acetone to prepare the polymer matrix of the PE system. Once the polymer was completely dissolved, a weighed quantity of the salt namely zinc triflate was added and dissolved completely. The resulting solution was cast into petri dishes and the solvent was allowed to evaporate in a vacuum desiccator at room temperature. Thin PE films of various compositions containing 5, 10, 15, 20 and 25 weight percent of zinc triflate in a polymer matrix of PVDF-HFP were prepared. The thickness of dried PE films measured using screw guage was found to be of the order of $80 \mu \mathrm{m}$. These PE films also exhibited good mechanical strength and stability.

\section{Characterization}

Detailed electrical conductivity analysis of these PE films was conducted using a computercontrolled Hewlett Packard model HP4284A Precision LCR meter over a frequency range of $20 \mathrm{~Hz}-1 \mathrm{MHz}$ within the temperature window 301-413 K to identify the optimum composition that yielded the maximum electrical conductivity. Each PE film was sandwiched between two stainless electrodes and held in place under spring pressure. The temperature regulation was done using a thermostat. The x-ray diffraction (XRD) patterns in the case of these PE films

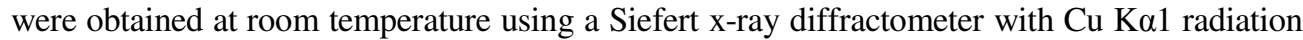
$\left(\lambda=1.541 \mathrm{~A}^{\circ}\right)$. The thermal properties of the membranes were studied using a DSC Q200 V24.10 build 122 differential scanning calorimeter. Each membrane was scanned from 223 $473 \mathrm{~K}$ at a scan rate of $10 \mathrm{deg} / \mathrm{min}$ under nitrogen atmosphere.

\section{Results and Discussion}

\section{Electrochemical characterization}

The complex impedance data in the case of PE thin film specimens at room temperature $(301 \pm 1 \mathrm{~K})$ were obtained in terms of impedance diagrams so as to determine the bulk resistance $\left(R_{b}\right)$ of these polymer electrolyte films. The $R_{b}$ value is given by the intercept obtained on the real axis in the plot of real versus imaginary component of impedance. The specific conductivity $(\sigma)$ of the PE films was then estimated using the relation ${ }^{13,14}$. 


$$
\sigma=l / \mathrm{A} \mathrm{R}_{\mathrm{b}}
$$

Where $l$ is the thickness of the PE and A is the area of cross of the electrode in contact with the film. Figure 1 shows the set of room temperature $(301 \mathrm{~K})$ complex impedance plots observed in the case of PE films containing 15, 20 and 25 weight percent of zinc triflate in PVDF-HFP polymer matrix. The value of bulk resistance was found to decrease with increase in the weight percent of zinc triflate in the various compositions of the PE system. Table 1 shows the variation of specific conductivity noticed for the series of PE films with varying weight percent of zinc triflate at room temperature and it is quite obvious that conductivity increases with increase in the zinc triflate concentration.

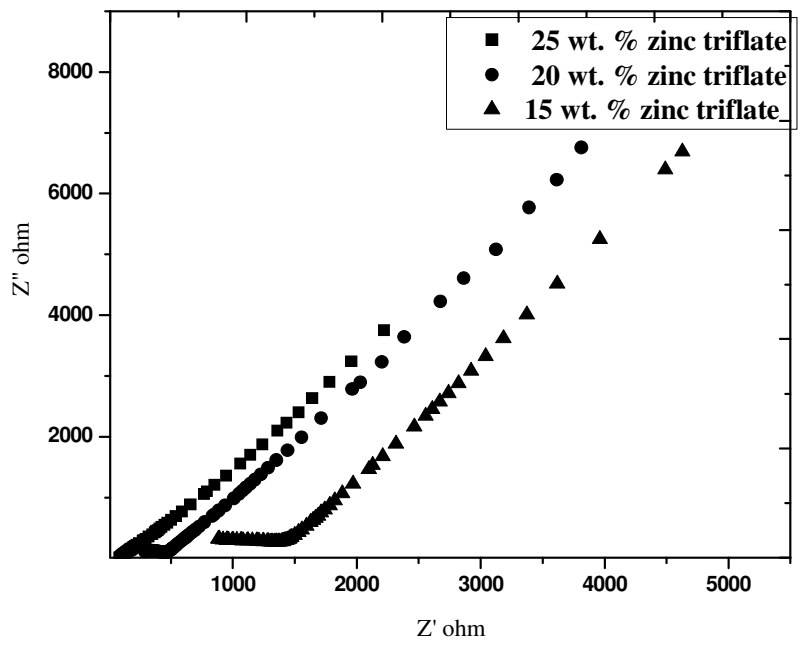

Figure 1. Complex impedance plots of PE films containing 15, 20 and 25 weight percent of zinc triflate at room temperature $(301 \mathrm{~K})$

The observed increase in the value of ionic conductivity may be attributed to the most probable increase in both ionic mobility and the concentration of carrier ions ${ }^{15}$. The concentration of mobile $\mathrm{Zn}^{2+}$ ions in the polymer matrix of the PE films analyzed is expected to increase as the concentration of zinc triflate in the sample increases ${ }^{16}$. The highest conductivity was shown by the typical PE film containing 25 weight percent of zinc triflate in the case of PVDF-HFP polymer matrix.

Table 1. Electrical conductivity values of PE films containing 5, 10, 15, 20 and 25 weight percent of zinc triflate in PVDF-HFP polymer matrix at room temperature $(301 \mathrm{~K})$

\begin{tabular}{cc}
\hline $\begin{array}{c}\text { Weight percent of zinc triflate } \\
\%\end{array}$ & $\begin{array}{c}\text { Room temperature electrical } \\
\text { conductivity }(\sigma) \mathrm{Scm}^{-1}\end{array}$ \\
\hline 5 & $7.9 \times 10^{-7}$ \\
10 & $1.2 \times 10^{-6}$ \\
15 & $5.1 \times 10^{-6}$ \\
20 & $1.4 \times 10^{-5}$ \\
25 & $5.5 \times 10^{-5}$ \\
\hline
\end{tabular}

The variation of specific conductance $(\sigma)$ with temperature for the best conducting composition showed Arrhenius type of thermally activated process as shown in Figure 2 and its activation energy (Ea) could also be calculated from the slope of the Arrhenius $\operatorname{plot}^{17}$. 


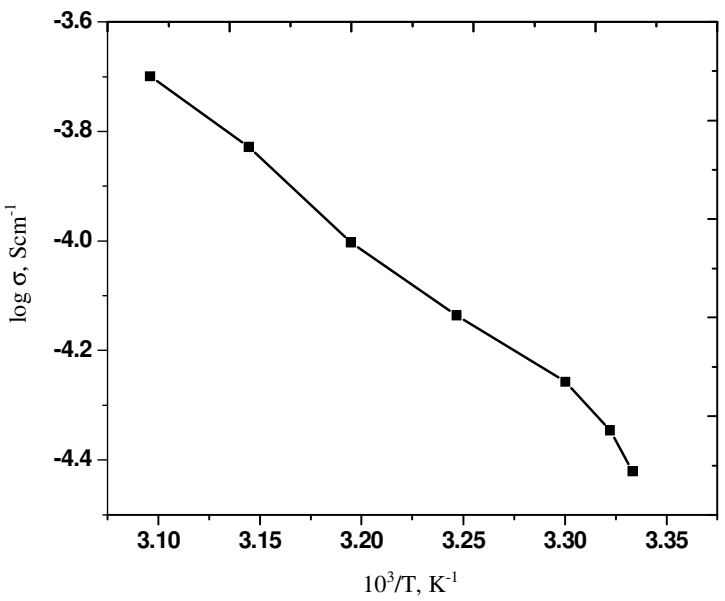

Figure 2. Variation of $\log \sigma$ vs. 1000/T for PE films containing 25 weight percent of zinc triflate in PVDF-HFP polymer matrix

\section{$X$-ray diffraction analysis}

Figure 3 shows XRD patterns of pure PVDF-HFP and PE films of zinc triflate containing 5, 15 and 25 weight percent of zinc triflate in PVDF-HFP polymer matrix with peaks at $2 \theta=19^{\circ}$ and $21^{\circ}$ corresponding to the semicrystalline nature of the polymer PVDF-HFP ${ }^{18}$. There is a relative lowering of peak intensity with increase in the concentration of zinc triflate. This feature may be due to a decrease in the crystalline nature, caused by the reduction in the long range order exhibited by pure PVDF-HFP. Furthermore, two peaks appear to merge and become a single broader peak with the addition of the salt which indicates that complexation between the chosen polymer and the salt has occurred. Interestingly, the absence of peaks corresponding to the salt appears to indicate that a complete complexation of the salt with the host polymer has taken place 9

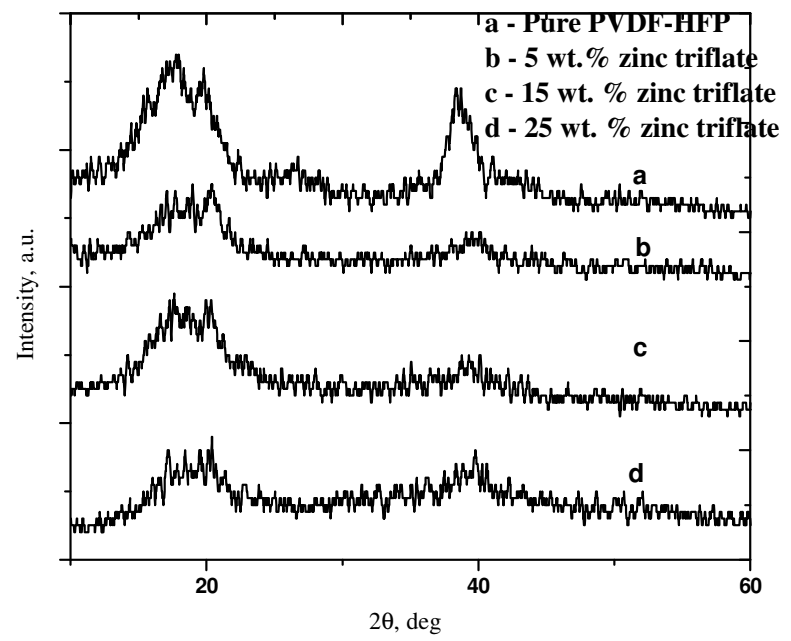

Figure 3. X-ray diffraction patterns obtained for pure PVDF-HFP and PE films containing 5,15 and 25 weight percent of zinc triflate in PVDF-HFP polymer matrix 


\section{Differential scanning calorimetry (DSC) studies}

Figure 4 shows the series of DSC thermograms obtained for pure PVDF-HFP and of PE films containing 5, 10, 15, 20 and 25 weight percent of zinc triflate in PVDF-HFP polymer matrix. All the PE samples show endothermic peaks around 403-423 K region which corresponds to their melting point. The endothermic peaks of PE films consisting of varying weight percent of zinc triflate in a polymer matrix of PVDF-HFP appear at values lower than the melting point of pure PVDF-HFP. This aspect indicates that a more amorphous phase is being formed when increasing amounts of the salt is mixed with the polymer. Due to the salt-polymer complexation the long range order as seen in pure PVDF-HFP tends to decrease. Further, the relative degree of crystalline nature is seen to decrease with increase in the zinc triflate (salt) concentration. This increase in the amorphous phase makes the electrolyte more flexible and facilitates segmental motion of the polymer thereby favouring an increased ionic conduction as well ${ }^{19}$.

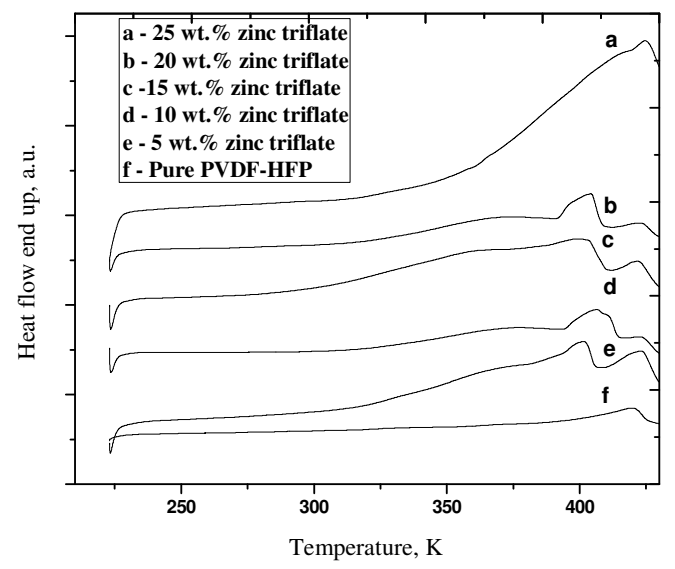

Figure 4. Differential scanning calorimetric (DSC) thermograms of pure PVDF-HFP and PE films of containing 5, 10, 15, 20 and 25 weight percent of zinc triflate in PVDF-HFP polymer matrix

\section{Conclusion}

From the present comparative analysis concerning samples with varying weight percentages of the salt namely zinc triflate within the polymer matrix formed by PVDF-HFP it has been inferred that the chosen polymer has readily formed stable complexes with the salt as confirmed by XRD and DSC data. The increase in observed electrical conductivity with increase in the concentration of zinc triflate salt could be attributed to a higher degree of amorphicity thus indicating the occurrence of zinc ionic conduction.

\section{References}

1. Gray F M, Polymer Electrolytes, The Royal Society of Chemistry, Cambridge, 1997.

2. Deepak Kumar, Mohd Suleman and Hashmi S A, Solid State Ionics, 2011, 202, 45-53.

3. Croce F, Gerace F, Dautzemberg G, Passerini S, Appetecchi G B and Scrosati B, Electrochim Acta, 2004, 39(14), 2187-2194.

4. Manuel Stephens A, Euro Polym J., 2006, 42(1), 21-42.

5. Fenton D E, Parker J M and Wright P V, Polymer, 1973, 14(11), 589.

6. $\quad$ Song J J, Wang Y Y and Wan C C, J Power Sources, 1999, 77(2), 183-197. 
7. Lizhen Fan, Zhimin Dang, Ce-Wen Nan and Ming Li, Electrochim Acta, 2002, 48(2), 205-209.

8. Hwang Yun Ju, Jeong Soo Kyung, Nahm Kee Suk and Manuel Stephan A, Eur Polym J., 2007, 43(1), 65-71.

9. Rudhziah S, Muda N, Ibrahim S, Rahman A A and Mohamed N S, Sains Malays., 2011, 40(7), 707-712.

10. Sim L N, Majid S R and Arof A K, Vib Spectrosc., 2012, 58, 57-66.

11. Guangchao Li, Zhaohui li, Peng Zhang, Hnaping Zhang and Yuping Wu, Pure Appl Chem., 2008, 80(11), 2553-2563.

12. Ikeda S, Mori Y, Furuhashi Y and Masuda H, Solid State Ionics, 1999, 121(1-4), 329-333.

13. Deka M and Kumar A, J Power Sources, 2011, 196(3), 1358-1364.

14. Sim L N, Majid S R and Arof A K, Solid State Ionics, 2012, 209-210, 15-23.

15. Ji Sun Oh, Jang-Myoun Ko and Dong-Won Kim, Electrochim Acta, 2004, 50(2-3), 903-906.

16. Girish Kumar G and Sampath S, Solid State Ionics, 2005, 176(7-8), 773-780.

17. Nithya H., Selvasekarapandian S, Christopher Selvin P, Arun Kumar D, Hema M and Prakash D, Physica B, 2011, 406(18), 3367-3373.

18. Saikia D and Kumar A, Electrochim Acta, 2004, 49(16), 2581-2589.

19. Noor S A M, Ahmad A, Talib I A and Rahman M Y A, Ionics, 2010, 16(2), 161-170. 